\title{
FAZER UMA OBRA NO TEMPO
}

\author{
Céline Masson * \\ Tradução: Sabira de Alencar Czermak**
}

\section{Resumo}

Mostramos que uma imagem, a partir do momento em que é captada pelo aparelho psíquico, é sempre tomada em um tempo não cronológico, mas anacrônico, que é a temporalidade própria à memória tal como Freud a definiu. A imagem no tempo psíquico e visual é uma imagem-traço, que drena para si as ínfimas partículas da realidade que servirão de ponto de passagem entre o dentro e o fora. Fazer uma obra é tomar algum tempo e modificá-lo pela forma plástica/estética. Quando o sujeito faz uma obra, ele capta e, ao mesmo tempo, se refaz daquilo que fez traço (no sentido do traço mnésico), ele se apropria pela sensação (estética) dos acontecimentos de sua história. A criação é um processo de tempo, de futuro, logo, de presente. A imagem é projeção para um porvir que traz consigo os traços do passado. Ela faz face a um novo ponto de vista, a novas imagens.

Palavras-chave: imagem; temporalidade; traços; criação; obra; fazer-obra.

\section{Abstract}

TO MAKE A WORK IN THE TIME

We show that an image from the moment it is picked up by the psychic apparatus, it is always taken in a non-chronological time, but anachronistic, that is the temporality of memory as Freud defined it. The image in time psychic and visual image is a trace, which itself drains into the tiniest particles of reality, which will serve as a crossing point between the inside and outside. Making a book is taking some time and modify it the way plastic / aesthetic. When the subject does the work, he captures and at the same time, he did what he relishes dash (towards the memory trace), he appropriates, the feeling (aesthetics), the events of history. The creation

* Mestre de conferências na Université Paris-Diderot, psicanalista, corresponsável do Grupo de Pesquisa Pandora sobre os processos de criação, membro do Centre de Recherches Psychanalyse, Médecine et Société, École doctorale Recherches en psychanalyse, Université Paris-Diderot. Psicóloga em L'OSE (Oeuvre de Secours aux Enfants).

** Psicóloga. Mestre em Saúde Coletiva. IMS/UERJ. 
process is a time in the future, so as a gift. The image is projected for a future that carries traces of the past. She bears a new point of view, the new images.

Keywords: image; temporality; trace; creation; work; make-work.

Mais une raison plus grave expliquait mon angoisse; je découvrais cette action destructrice du Temps au moment même où je voulais entreprendre de rendre claires, d'intellectualiser dans une ouvre d'art, des réalités extra-temporelles. (Proust, 1989: 236-237) ${ }^{1}$.

Fazer uma obra é tomar tempo e modificá-lo pela forma plástica/estética. Dar forma pelo traço é captar, capturar por antecipação um acontecimento. E, na medida em que o traçado é captura, a imagem afirma-se em primeiro lugar como o assassinato da coisa representada. A criação é um processo que remete ao tempo, ao futuro, logo ao presente. A imagem é pro-jeção para um porvir que traz consigo os traços do passado. Defronta-se com um novo ponto de vista, novas imagens.

É necessário depositar o tempo na imagem para dela extrair sua verdade. A imagem pintada é o depósito que guarda os traços dos acontecimentos que ocorrem ao sujeito e sua superfície os retém para evitar a destruição. Os traços do tempo (invisível) são o material com que se cumpre a representação (visível). A imagem agarra o tempo e o impele no túmulo da obra. O olhar ali recai, intemporal, eternizado pela imagem que o capta. O sujeito experimenta o tempo sem ter o tempo de ver. Toda imagem toca à imagem originária do mito que lhe dá sua contextura (sua matéria plástica), tomada de chofre no pathos. A imagem é um lugar para o mito, sendo a origem o centro de tal imagem. Nesse sentido, a origem como "ponto de fuga”, diria Pierre Fédida, é geradora de formas. Na medida em que contém a ausência, a imagem tomada no mito das origens é suporte do figurável.

\section{O Lugar da obra}

Escrever-desenhar significa agrimensar lugares desconhecidos, inventar desertos e cartografar regiões perdidas. Ao fazer uma obra, abrimos vias desconhecidas e fazemos emergir um fundo, a própria matéria do vivo. Nela, a obra se abre e, através disso, se engendra. O fundo da obra é a pele, na superfície há o fundo da obra, sua própria essência. A superfície revela a atividade do fundo, o trabalho do fundo, sua emergência na direção da forma e para a forma. A obra 
é a aparição de um acontecimento, ou seja, um momento de real tomado em sua realidade, antes de sua conversão ao objeto. A obra retoma, no seu movimento, elementos do real que, fora dela, permaneceriam desconhecidos. A partir dela, esses elementos ficam em presença e entram em contato. A obra abre um espaço e o espaço engendra um ritmo e este, a pulsação psíquica pela qual a obra é criada. Uma obra é um monstro tópico, lugar paradoxal do agora e do outrora, entre presença e ausência. Através do olho edifica-se uma obra singular que porta sentido no silêncio da história, onde cada um tem suas marcas. O sujeito criador da obra tem então a obra como objeto e fica apendente a esse acontecimento advindo da obra enquanto acontecimento psíquico. O que surge é um apelo a e por si. Apelo ao Outro para o qual o sujeito está apendente por sua demanda. Um apelo a captar novamente pelo ser-obra da obra na intensidade do seu endereço. Tal acontecimento é uma rasgadura na história de um sujeito; no aberto dessa rasgadura é que aparece o sujeito do enigma.

Toda obra aparece na abertura dessa rasgadura, ali, precisamente, onde o sujeito deposita sua questão. O sujeito é alçado a uma forma de existência que ele descobre ser sua, na surpresa do acontecimento da obra. (Com) preender uma obra, isto é, captá-la, implica tomá-la em si no espaço da rasgadura, esse espaço aberto no coração do íntimo. E é nesse lugar, no coração do íntimo, que a obra toma rosto. Colocá-la à vista para um outro olhar é a ocasião para desnudá-la em seu aparecer, esse tempo da (em)-formação. A obra é uma forma em formação, a figura de um movimento psíquico oriundo do encontro entre o psiquismo e o mundo ambiente. É uma forma de relação essencial entre o dentro e o fora. Tal forma é uma impressão de tempo, do tempo originário no seio da vida psíquica.

A obra enquanto forma sobrevivente existe ao abrir uma via, a via de sua própria constituição. Nesse sentido ela (ex)-iste, ou seja, se mantém fora. Memória e obra são indissociáveis. Trabalho de obra é trabalho de memória, no sentido em que memória designa o não abandonar, o que tende para... Ela vira e se desvira na direção de um tempo inatual para ( $r e$ )-conhecer o que escapou. A obra é precisamente a coletânea do que escapou e sua captação, a comemoração de acontecimentos passados. A obra devolve um olhar à unidade desaparecida. Unidade ou fragmento de um conjunto desaparecido e que, no entanto, compóe a obra e a decompóe. Construir uma obra é juntar fragmentos heterogêneos surgidos não se sabe de onde, mas mobilizados em favor desse ato de criar. $\mathrm{O}$ ato articula esses diferentes elementos através de um retorno em si mesmo, ao mais íntimo de si, e tende a compor um lugar para a figuração. A forma em formação, a forma de história em devir é o lugar de encontro do corpo e do espaço com o qual ele conasce ${ }^{2}$. A obra como monumento guarda a memória de sua origem, ou seja, a matéria bruta, a 
matéria de escrita ou de impressão da qual nascem os rostos. Os rostos da obra ou para a obra na escrita por nascer.

$\mathrm{O}$ artista faz nascer uma matéria, uma matéria com rosto e para um rosto in absentia. Em seguida, essa matéria se "individualiza" em uma forma que tende à figura. A obra surge da matéria que se abre em um espaço de possíveis, momento rítmico. O movimento é então possível no vazio da obra; é também a partir daí que sopra a imagem (para retomar a bela expressão do "sopro indistinto da imagem" de Pierre Fédida). Da verticalidade da obra emergem as figuras do vazio. Tais corpos animados se estendem, para além de si, na direção desse apelo em vista, esse apelo a se abrir. A obra é um apoio no tempo. Cada obra testemunha o temor desse tempo, um tempo do monstro ao extremo do que podemos suportar. A experiência da obra contém um monstro através do qual o real se vincula. $\mathrm{O}$ real através do que a obra resplandece e os monstros dissimulados pelo trabalho do tempo chegam à superfície. A obra é a obra do estilhaço, ou seja, esse real que incisa sua matéria e traz para a luz do dia os monstros do tempo. É unicamente essa incidência entre o vivido psíquico e o real que determina o que uma obra terá que ser. $\mathrm{O}$ que entra em contato com a obra é o espaço-tempo que impõe seu ritmo e trabalha sua matéria. A tensão entre a forma e o fundo da obra é a relação entre tempos internos e a superfície do visível. A dimensão de uma obra é seu ritmo e seu espaço, engendrado pelo ritmo. A obra de arte realiza o espaço e então realiza o ser; ela se abre, pois, para a existência que é relação entre a essência e o fundo. A obra, por sua abertura, des-cobre um rosto, o da ausência. $\mathrm{O}$ rosto, ausente, é a presença da obra em sua necessária desaparição, pois, ali onde há uma obra, há um sujeito que se ausenta.

A forma criada é forma de si, forma a-ser pela obra. Não se trata de começo, porém de origem, de origem a-ser precisamente; a forma em formação a que remete a origem. A origem é a forma em presença, por-vir, uma forma em formação de presença. É a forma que cria a presença e, a partir daí, a origem entra no lugar da ausência. No coração da forma está o vazio do sujeito em que ele surge, pois é no vazio da forma que nasce a linguagem. A obra é a ocasião ou o acidente de um rosto, ela está em vias de um rosto que tem que surgir, ou não há obra. A obra da obra é a essência de um rosto. Ela é momento de realidade do sujeito e é este que a arte torna visível, segundo a fórmula de Paul Klee.

O traçado de uma forma é um devir de presença no plano háptico e não somente ótico, ou seja, no plano das percepçóes do tato. $\mathrm{O}$ contato garante a permanência da forma que o fundo suporta. A partir de um fundo semelhante, em contato com a parte de cima tátil, é que o motivo se move. A experiência estética revela ao sujeito seu ponto de apoio [point de chute], seu lugar e sua falha, ali onde 
isso faz sintoma: cair em sintoma, "estar estupefato", e sumptôma, "acidente, coincidência”. Essa experiência é a experiência de uma queda, uma experiência vertical. A forma em formação na obra é um momento de abertal para o sujeito criador que reintegra a forma assim produzida. A obra se retira e a forma nele inter-vem no contato com o psíquico, que é produto da construção de níveis onde cada forma encontra seu lugar. A arte é a abertura de um lugar. Heidegger dizia justamente que a obra instala um mundo.

A arte põe em vista um lugar, o lugar do ausente, ao traduzir visualmente uma imagem de linguagem. É através de um jogo metafórico que o sujeito criador faz advir a forma interna, no intuito de deixar descobrir a forma psíquica. A matéria da arte é a descoberta do psíquico que aponta para o vivo da Coisa. A coisa da obra, diz Heidegger, é a matéria informada, suporte da criação artística. A forma é o que vai ordenar a matéria no tempo, em um contorno determinado. A atividade artística é pôr em obra a verdade, verdade da obra que é também uma verdade intemporal. Todavia, o artista trabalha o tempo como uma matéria e a obra abre o tempo na imagem. O lugar da Coisa é um lugar de angústia, no sentido de ausência de lugar ou de presença demasiadamente grande, presença plena a sufocar. $\mathrm{O}$ próprio de um determinado lugar é abrir, abrir sobre o "si mesmo", como o sonho de uma sombra. A obra, em sua matéria, implica em sensações de contato com o outro no mesmo, sensaçōes muito primitivas que fazem a matéria do quadro. A arte revela o vazio, testemunha o nada e começa a via. A abertura de uma obra é uma autogênese pontuada por momentos rítmicos, através dos quais o espaço se modifica. A arte põe à vista na medida em que o espaço da obra abre um lugar de aparição pelo qual entram os rostos da ausência. O que se ergue então na obra é essa presença longínqua no limiar do visível.

\section{IMAGEM, CRIAÇÃO, TEMPORALIDADE}

[...] comment la laideur du monde est-elle possible? J'ai usé de la volonté de créer du beau, de la volonté de demeurer dans des formes identiques comme d'un moyen provisoire de conserver et de guérir. Mais la force d'éternelle création, qui n'est autre que l'obligation de détruire éternellement, m'a toujours semblé fondamentalement liée à la douleur. Le laid, c'est une façon d'envisager les choses avec la volonté d'introduire un sens, et un sens nouveau, dans ce qui a perdu toute espèce de sens; c'est la force accumulée qui oblige le créateur à sentir que le passé est intenable, manqué, digne d'être nié - laid.

(Nietzsche, 1995: 37) ${ }^{3}$. 
A criação é um processo de recondução das forças pulsionais, de composição de um corpo no fora, na estranheza de um lugar do íntimo. $O$ ato de criar recomeça, para retomar Blanchot, o passado que se abre ao futuro (Blanchot, 1959a: 27). O que é interior toma a forma de uma imagem, diz ainda o autor. Esse fora interior é um corpo do dentro, de extimidade [extimisé] que atribui um sentido novo ao lugar do corpo, que reconsidera os lugares do corpo. Essa colocação em corpo no exterior é o que convoca o mais íntimo. $O$ fora nos espera dentro e os artistas sabem disso. É o que faz ainda o ato criador ser um ato perigoso e engajado do ponto de vista do inconsciente. $\mathrm{O}$ trabalho de criação desfigura a excessiva figura ("força acumulada" de que fala Nietzsche) projetada no espaço. Esse "sonhador à luz do dia" de que fala Freud, a respeito do criador, é aquele que pode dar, em um tempo anacrônico, um corpo às imagens de sua fantasia. A obra, como, aliás, o sonho e o sintoma dão uma borda ao fluxo pulsional pela transfiguração.

Para Konrad Fiedler (Fiedler, 2003: 63), primeiro filósofo da arte cujo objeto de estudo foi especificamente as artes plásticas e, portanto, a que remete diretamente à visibilidade; a arte é uma necessidade, trata-se de um Bedürfnis, nos diz Danièle Cohn em seu prefácio ou, colocado de outro modo, o artista é impulsionado a fazer-obra, a devolver a imagem e isso remete a uma obrigação fisiológica. Reencontramos, aqui, nossas Triebe freudianas, significa tratar-se de uma ação pulsional que redefine sem cessar uma certa configuração psíquica.

Fiedler se opôs a qualquer esteticismo, à arte considerada como suplemento de alma. Com Fiedler estamos mais próximos daquilo que Lacan nomeia o maisde-gozar, que não é um pequeno prazer, mas a distribuição do prazer no corpo: é o efeito do que é eludido no discurso, passado em silêncio. É o que pesa no estômago, dirá ainda Lacan ao revisitar o texto de Freud sobre "Os chistes e sua relação com o inconsciente". A atividade que produz o visível é descrita por Fiedler em termos de pulsão, de necessidade e de força. A forma transporta consigo o conhecimento que adquiriu pelo sentido, mas o interesse é levado ao alcance da intersubjetividade. Ele escreve: "Nous sommes dans la vie continuellement livrés à des excitations esthétiques, équitablement transmises par nos cinq sens [...]. Toutes les impressions sensibles s'accompagnent d'une sensation esthétique située quelque part entre les deux extrémités de la gamme, le plaisir et le déplaisir" (Fiedler, 2004: 37)4.

Uma teoria da arte para Fiedler deve interrogar-se sobre o ato criador e a temporalidade de seu processo, ou seja, a transposição em imagem daquilo que seu olho permite ver (ideias, imagens mentais). Manter-se o mais próximo possível daquilo que o artista "traz para o visível", segundo a expressão de Danièle Cohn, daquilo que traz ao visível proveniente de uma temporalidade interna. $\mathrm{O}$ artista persegue o movimento temporal até a expressão, a depender de uma bem dita 
"lógica do olho". (Cohn, prefácio em Flieder, 2004: 23). Conforme Fiedler sustenta, aquilo que nós possuímos da realidade é resultado de um processo interior. $\mathrm{O}$ acesso às formas é dado pelo movimento formal/temporal. O artista é quem dá formas para testemunhar sua relação com a realidade e seu contato (corpo a corpo) com o mundo e os objetos que o cercam. Significa ir até as coisas através das formas, conclui Danièle Cohn na forma interrogativa. De fato, tratar-se-ia para o artista de ir à própria Coisa (das Ding, erguendo o objeto até ela) por essa pulsão de fazer-forma pela obra e pelo olho. Rendemo-nos à evidência de que a criação de formas para o artista está diretamente indexada à pulsão escópica. "Veut-on à présent connaître la mise en forme d'un être sensible dans les divers aspects de sa constitution sensible, le mieux est d'envisager en particulier un de ces aspects: la visibilité" (Fiedler, [1887] 2003: 63) ${ }^{5}$. E mais longe: “[...] l'homme ne peut développer ses images visuelles à un degré supérieur d'existence que grâce à une activité qui produit une configuration visible et vérifiable comme telle; cette activité n'étant rien d'autre que l'activité artistique" (Fiedler, [1887] 2003: 63) ${ }^{6}$. Assim, a atividade artística produz uma configuração visivel que permite confrontar-se às imagens visuais psíquicas.

"L’immense empire du monde visible tout entier se révèle dépendre de la matière la plus délicate et pour ainsi dire la plus incorporelle, et ses formes sont liées aux formations que l'individu crée en tissant cette matière" (Fiedler, [1887] 2003: 69) ${ }^{7}$. O que a realidade oferece através da vista, como diz Fiedler, poderá alcançar uma forma de expressão plástica. O poder sensível se enuncia quando ele acede à vista. Ou ainda, o contato que a sensação estabelece com a vista permite a criação de representações escópicas. E a apresentação do objeto visível à vista augura outros objetos que serão objetos de criação de formas novas (diferentes do que constituía a representação visual). Vemos que diferentes tempos escópicos são necessários para chegar a uma forma de criação plástica: da percepção visual à criação de representações visuais e enfim à criação-fabricação de objetos capazes de testemunhar, em sua forma e sua matéria, a impressão da realidade sobre a vista. Para Fiedler, a vista é esse "domínio sensível" que permite a passagem entre "os processos interiores (sentir, perceber, representar) e as atividades exteriores (apresentar, captar e dar forma) [...]" (Fiedler, [1887] 2003: 77). Essa passagem entre o interior e o ato exterior é criadora de processos complexos. Trata-se ainda, diz Fiedler, de fazer do visível uma apresentação visível que apenas os produtos da atividade plástica realizam. A mão persegue o trabalho do olho. É Fiedler quem escreve:

Ce qui, dans certains mouvements d'expression, reste esquissé d'une manière vague chez tous les êtres humains aboutit chez l'artiste à un développement 
exclusif et tout à fait exceptionnel; [...] Nous autres, nous sommes bloqués dans les perceptions que notre œil nous offre et notre pouvoir de représentation visuelle a tôt fait d'y trouver sa limite, une obscurité impénétrable nous paralyse. L'artiste, au contraire, trouve en lui les moyens d'exprimer et de saisir de plus en plus précisément ces processus vagues et indéterminés, par lesquels nous percevons globalement un monde visible (Fiedler, [1887] 2003: 87) ${ }^{8}$.

A atividade artística inicia-se nesse ponto de sombra em que, para além do visível, o artista se aventura. Ele toma sua vista no ilegível da letra rumo à intensificação da forma plástica.

O artista (ex)-põe, no visível, o trabalho da figura que toma corpo na memória da vista. Memória das imagens sobreviventes e das ausências errantes nessa trama que constitui o próprio nó da história. As representaçôes mentais entram em contato com movimentos do corpo-visão que irão traçar o movimento interno do olhar de memória. Fazer o contato é determinante para a criação de figuras. Vê-se que o tempo artístico é um tempo de elevação de memória, de fantasmas de memória na direção de figuras de tempo. Para Fiedler, a atividade plástica do artista é como o prolongamento do processo visual, "comme le développement en des mises en forme déterminées de ce qui naît dans la perception de l'œil" (Fiedler, [1887] 2003: 89) ${ }^{9}$. Quando a "natureza humana", diz Fiedler, dedica-se à atividade artística, ela deve deixar a "luz do dia da consciência" para se abrir às "forças misteriosas". "A aparição fugidia" nasce a partir da percepção visual que a sustenta, percepção esta que, embora voltada para o exterior, desenvolve uma atividade interna autônoma; em suma, trata-se de uma interface. Dessa experiência visual interior depende a vida das formas e, portanto, a experiência plástica. A experiência interior constitui um verdadeiro teatro em que imagens fantasmáticas de coisas visíveis surgem e, conforme a formulação admirável de Fiedler, "menant dans leur foule bariolée un jeu de fantaisie et d'arbitraire" (Fiedler, [1887] 2003: 101) ${ }^{10}$. As formas artísticas são suportes de impressões de formas interiores. A tarefa do artista é (re)-unir o visual e o não-visual e transformar uma forma interior em uma "unidade" nova. A obra é o resultado de forças históricas transindividuais que testemunham a História (com um grande machado, como retomava Lacan citando o poeta ${ }^{11}$. A memória do artista é uma superfície visual de ressonância, na qual se forma o nome das coisas vistas.

\section{IMAGEM DE TEMPO E FANTASIA}

"Qu'est-ce que l'on a, de soi, à transmettre? - Sans doute rien; mais ce Rien est tout ce que nous possédons" (Jabès, 1984: 138) ${ }^{12}$. O tempo trabalha 
a imagem, faz dela um espaço visual onde agem diferentes operações psíquicas que podem operar reunindo fragmentos tirados de espaços modificados, anacronismos, superposiçóes... O tempo da obra na imagem transporta uma força capaz de modificar as figuras que elas re(a)presentam. Tal encenação temporal de imagens é uma expressão sintomática da matriz fantasmática. Na permanente desconstrução dos espaços criados pelo tempo surge, então, o potencial criador das imagens e a dimensão poética das figuras. Essa matriz engendra formas e imagens pelo trabalho do tempo.

Ver é se pôr em contato com a coisa perdida, é um ato temporal. A imagem não toma apenas sua vista na experiência do espaço, ela é extraída de camadas da memória, da matriz inconsciente, organização de contatos através de atos temporais. $\mathrm{Na}$ ausência, as imagens alcançam a vista do sujeito, no próprio tempo em que o sujeito tem uma ausência. Esse momento de ausência pode ser um momento de encontro com si mesmo, em que precisamente ali eu desfaleço por demasiada "lucidez", para retomar a palavra de Van Gogh: "J'ai une lucidité terrible par moments, lorsque la nature est si belle de ces jours-ci et alors je ne me sens plus et le tableau me vient comme dans un rêve" (Van Gogh, [1956] 1988: 420) ${ }^{13}$. Por estar presente demais a si mesmo, por exemplo nesse momento de vista plena, "quando a natureza é tão bela", o sujeito não cabe em si e, na ausência, pode surgir o quadro ou a imagem do sonho.

É no tempo do encontro com a natureza, por exemplo, com o belo (o presente do presente), que paradoxalmente alguma coisa do tempo presente se interrompe para se abrir ao tempo da imagem reminiscente. Uma presença de imagens (o presente do passado) à vista que surgem nessa ausência, quando a vigilância após tensão intensa cede diante do belo. Não é tanto a contemplação que provoca a imagem (de baixo), que a desaloja desse canto de sombra, mas a atenta observação que vem tornar possível a abertura da memória e a mobiliza em suas camadas (presente do futuro). A atenção presente faz passar o que estava por vir, para, então, tornar-se passado. E o passado, sempre em atividade, faz sua impressão na superfície do visível e do sensível.

Sabe-se, com Freud (Freud, [1908] 1985), que o desejo se utiliza de uma ocasião do presente para esboçar uma imagem de futuro segundo o modelo de passado. A fantasia se ativa pelo desejo e a imagem onírica da noite, como a do sonho diurno são construídas com o mesmo material, a Phantasie, termo alemão que designa o mundo imaginário e seus conteúdos, a atividade criadora que o anima. Freud explorou seus diferentes usos. Referindo-se à concepção da temporalidade psíquica, ele escreve: 
Le rapport de la fantaisie au temps est de manière générale très important. On peut dire qu'une fantaisie flotte en quelque sorte en trois temps, les trois moments de notre activité représentative. Le travail psychique se rattache à une impression, une occasion dans le présent qui a été en mesure de réveiller un des grands désirs de l'individu; à partir de là, il se reporte sur le souvenir d'une expérience antérieure, la plupart du temps infantile, au cours de laquelle ce désir était accompli; et il crée maintenant une situation rapportée à l'avenir, qui se présente comme l'accomplissement de ce désir, précisément le rêve diurne ou la fantaisie, qui porte désormais sur lui les traces de son origine à partir de l'occasion et du souvenir. Passé, présent, avenir donc, comme enfilés sur le cordeau du désir qui les traverse (Freud, [1908] 1985: 39) ${ }^{14}$.

É a ação do fantasma, imaginá-lo animado pelo desejo. Esse phantasieren de que nos fala Fred, que tece conjuntamente os três momentos temporais da representação, a fim de que componham um único movimento.

Para retomar o que diz Van Gogh, "a natureza é tão bela”, e "não caibo em mim", "e o quadro me vem como num sonho", vê-se a força do encontro entre aquilo que ocorre de belo aos olhos no instante presente e aquilo que retorna, de longe, de um passado presente alçado à palavra: essa imagem leve, bela, pois vinda de longe e conduzida pela aura dos amores da infância (por vezes nada, uma sensação nova, um desejo, um rosto...). Tempo de um encontro que se abre para o sonho, é condição e torna possível tal quadro de transferência. Um acontecimento passado é reelaborado e reinscrito através de um acontecimento atual e torna-se, por este, eficaz. Complexidade das sequências psíquicas que agem por entrecruzamento e reviravolta. Um sentimento de presença impóe-se e se estende na própria ausência da coisa que deixou rastro. Assim, dá-se a invasão, "não caibo em mim”, pois o muito longínquo do outrora se torna o muito próximo da visão, que então só pode ser bela: bela como reencontros de amigos muito próximos, se reencontrando após se terem perdido de vista. E o quadro que vem é essa passagem das imagens rumo à presença ausente na lembrança. Lévinas considera o fenômeno como o ser que aparece, mas permanece ausente. Poder-se-ia dizer que o quadro como fenômeno (ser obra da obra, como teria dito Heidegger) é uma figura aparecente da memória, mas que permanece ausente. $\mathrm{O}$ próprio da figura está em se descobrir e, na obra, ela se descobre ao se ausentar no lugar mesmo de sua aparição. Para Kant, o fenômeno é "objeto de experiência possível”, ou seja, tudo aquilo que aparece no tempo ou no espaço.

“Devant la nature c'est le sentiment du travail qui me tient. Mais enfin c'est pour te dire qu'en dedans de moi il doit y avoir eu quelque émotion trop forte, 
qui m'a foutu cela et je ne sais pas du tout ce qui a pu l'occasionner" (Van Gogh, [1956] 1988: 503) ${ }^{15}$. Face à natureza, ele não cabe em si e o quadro vem como num sonho. Contudo, ele expressa bem essa dimensão de trabalho sobre o motivo que lhe custa psiquicamente. É o que lhe custa uma vivência das emoções, após a visão fulgurante da natureza. Não seria esse momento em que ele não cabe em si uma defesa contra as emoções que lhe chegam à vista? Não mais caber em si, pois se está demasiadamente pleno e o risco torna-se reencontrar a "tão forte emoção que me meteu nisso...". Um campo de trigo ou de cipreste "valent bien de les regarder de près" [vale a pena olhá-los de perto] (Van Gogh, [1956] 1988: 507). O que é um campo de trigo ou de cipreste, que formas ele perceberia de perto? Temos talvez um elemento de resposta na carta seguinte em que ele diz:

Apprendre à souffrir sans se plaindre, apprendre à considérer la douleur sans répugnance, c'est justement un peu là qu'on risque le vertige, et cependant se pourrait-il, cependant entrevoit-on même une vague probabilité que dans l'autre côté de la vie nous nous apercevrons des bonnes raisons d'être de la douleur, qui vue d'ici occupe tellement tout l'horizon qu'elle prend des proportions de déluge désespérant. De cela nous en savons fort peu, des proportions et mieux vaut regarder un champ de blé, même à l'état de tableau (Van Gogh, [1956] 1988: 509-510) ${ }^{16}$.

Essa dor que ocupa todo o horizonte invade também o campo escópico, tomando proporções monstruosas, isto é, angustiantes e transbordantes. O campo de trigo, de perto, pode ser contido pela vista, dominável e de certo modo também tranquilizador pelas formas e cores que propõe.

A dor de que fala é provavelmente esse torpor melancólico de que fala também Celan em um de seus poemas (gekammerten Schmerz, a dor trancada). Diante do campo a perder de corpo da dor e da angústia, sem proporções, ele se põe diante do campo de trigo, mas suficientemente próximo para não ser invadido pelo ilimitado do campo. Olhar de perto permite distinguir as formas e sua variabilidade, permite ponderá-las através da vista e expressar uma versão sobre a tela ou o papel. O campo de trigo é uma figura da memória, é uma de suas expressões, pois muito perto das formas são outras formas que surgem (Proust fará disso uma admirável demonstração).

Os momentos de crise ("terrible et alors je perds connaissance de tout" [terrível e então perco consciência de tudo]) (Van Gogh, [1956] 1988: 531) vão impulsionálo para o trabalho como "un charbonnier toujours en danger se dépêche dans ce qu'il fait..." [um carvoeiro sempre em perigo se apressa no que faz...] (Van Gogh, 
[1956] 1988: 531). Diante do perigo da dissolução psíquica, do aniquilamento (perder consciência de tudo), o trabalho se impõe com urgência para realimentar o fogo da vida psíquica (o amarelo, cor muito utilizada por Van Gogh, serve para representar o amarelo dos campos de trigo, o sol e seus raios). Aliás, ele dirá: "C'est cela qui me tient encore relativement en équilibre [...]" [É isso que me mantém relativamente ainda em equilíbrio] (Van Gogh, [1956] 1988: 536).

A melancolia o "toma forte", com "grande força" e, em seguida, nos momentos de trégua, quando a "saúde volta ao normal", ele se dá conta de que pintar é "como uma loucura", "uma coisa contra a razão". Parece-me que essa "loucura" criativa vem na continuidade da outra loucura demolidora, que é a crise melancólica; o faz, porém, para modificá-la, (re)introduzindo bordas (o que chamo de enformação) para que um eu possa, ali, se (re)inscrever. "Então me sinto todo triste", diz ele, esse "todo triste" que é mais próximo de um sentimento, de uma emoção mais suportável do que a "perda de consciência” que ele mencionava.

\section{O QUE QUER UMA OBRA?}

"Que peut", interroge Blanchot, "nous apprendre l'œuvre d'art qui puisse nous éclairer sur les relations humaines en général?” (Blanchot, 1959: 42-43)17. Ele afirma justamente que uma "exigência" se anuncia a qual poderá ser "captada" por formas criativas e, como clamava Rilke ao jovem poeta: "[...] édifier votre vie selon cette necessite" [edificar sua vida segundo tal necessidade] (Blanchot, 1959: 44). Kafka fala de "mandato" que ele assume diante dessa exigência de escrita. Mas tal exigência contém contradições, e o criador é com frequência desalojado de seu eu. $\mathrm{O}$ que o criador expressa ao exigir assim é ele mesmo, sua intimidade mais profunda e ao mesmo tempo longínqua, seu "Je' longínquo, informulado, informulável" (Blanchot, 1959: 46).

Mas aquilo com que o criador se confronta é a fissura, essa fissura do eu que remete a uma falta inapreensível cavada pela angústia. Artaud escrevia contra o vazio, contra a angústia, no intuito de conjurá-los. Ele afirma querer superar "ce point d'absence, d'inanité. [...] ce creux, cet intense et durable néant... Je ne puis ni avancer ni reculer. Je suis fixé, localisé autour d'un point toujours le même et que tous mes livres traduisent" (Blanchot, 1959: 56-57) ${ }^{18}$. Esse estado de crise, de remanejamento psíquico, de reviravolta temporal é também um estado propício à criação. Ele trava combate e não renuncia à vida, essa lâmina de vida que ameaça a cada instante. A situação geográfica do escritor é aquela do não-lugar, do exílio, em tensão entre o dentro de si e o fora de si. 
Em La volonté de puissance (Nietzsche, 1995: 217-436), Nietzsche escreve que o material constitui uma espécie de movimento sintomático revelador de um fato desconhecido. Esses movimentos são sintomas, pois nos permitem captar desejos. O sintoma enquanto aquele que abre a via para a verdade do inconsciente. O fazer-obra torna possível tais movimentos, pois o criador trabalha a matéria em tomada direta com os sintomas. Trata-se de uma "força plástica", para retomar a expressão de Nietzsche, que organiza a matéria sintomática. Força que quer criar, "monstro de força", "soma fixa" que se transforma sem perda. Jogo de forças e de ondas de força em fluxo perpétuo, em eterna mudança e refluxo. "Mar de forças" no fluxo e refluxo de suas formas. Nietzsche chama isso de seu "universo dionisíaco", o que se cria e se destrói de maneira contínua. Ele fala também de "vontade plástica" que impulsiona à ação da forma através dessa ritmicidade de fluxo, por esses movimentos encadeados. As coisas são móveis, diz ele, tudo se dissipa e se encarquilha em permanência. $O$ processo vital, fenômeno temporal, é essa força de formação que cria as formas do dentro utilizando as circunstâncias exteriores. Parece-me que ele descreve aí o processo mesmo do fazer-obra, essa formação de formas plásticas/psíquicas em contato com acontecimentos de tempo. Encontro de fluxo - fluxo de tempo histórico e fluxo de tempo psíquico, cujo contato é formador de formas inéditas, sempre novas, que contribuem para formar também uma temporalidade própria àquela do processo plástico.

Nietzsche fala justamente de "formes neuves" [formas novas] (Nietzsche, 1995: 240), modeladas por essa força interna ou ainda de "force plastique inconsciente" [força plástica inconsciente] (Nietzsche, 1995: 251) necessária à criação plástica: "Il semble qu'un même instinct esthétique pousse l'artiste à idéaliser la nature et l'homme à s'envisager, lui et la nature, sous une forme imagée. Finalement, c'est cet instinct qui a dû causer la construction de l'?il. L'intellect apparaît comme la conséquence d'un appareil qui était esthétique à l'origine" (Nietzsche, 1995: 251) ${ }^{19}$. As formas são talhadas por essa força plástica inconsciente, essa força que vê por detrás da memória, enquanto as imagens chegam como um estilhaço emergindo da força dos bastidores e do "mundo exterior". Sendo as imagens um produto da imaginação, diz Nietzsche, o artista faz vir as formas que lhe re(a)presenta sua imaginação e as "reforça". As formas representam os movimentos de tempo psíquico e testemunham uma força, um "querer interno", como diz Nietzsche (querer que ele chama de "vontade de potência").

Para Nietzsche, a embriaguez é a condição de um corpo excitado, necessária em qualquer ato estético. Tal excitação intensifica as emoções e os afetos em favor de um mais-de-gozar pelo olhar. $\mathrm{O}$ ato criativo é um olhar ativo sobre o mundo, de cara a cara com o mundo. A embriaguez da excitação sexual é a forma mais 
antiga e primitiva da embriaguez. Embriaguez das emoçōes fortes (festa, duelo...) e da extrema agitação da alegria à cólera que produz esse distúrbio corporal, condição mesma da criação. Tal embriaguez produz "l'intensification de la force" [a intensificação da força] (Nietzsche, 1974: 63), da força criativa, um sentimento que engaja o artista "nas coisas". Esse estado intensifica o olhar, infla o eu: "L'homme qui connaît cet état transfigure les choses jusqu'à ce qu'elles lui renvoient l'image de sa puissance - jusqu'à ce qu'elles ne soient plus que des reflets de sa perfection" (Nietzsche, 1974: 63) ${ }^{20}$. Dois modos de embriaguez são introduzidos pelas noções de apolíneo e de dionisíaco:

L'ivresse apollinienne excite surtout l'œil, qui en reçoit le pouvoir de vision: le peintre, le sculpteur, le poète épique [...]. Dans l'état dionysiaque, au contraire, c'est l'ensemble de la sensibilité qui est excité et exacerbé au point de décharger d'un seul coup ses moyens d'expression et d'intensifier à la fois son pouvoir de représentation, d'imitation, de transfiguration, de métamorphose, tous les modes de l'art du mime et du comédien (Nietzsche, 1974: 64) ${ }^{21}$.

\section{OBRA E TEMPORALIDADE}

Como compreender temporalidade e obra? Essa relação consiste em pensar o tempo como aquilo que existe em si de inassimilável, de radicalmente outro, ou seja, o que não se deixa compreender. Relação com o (In)-visível, diria Lévinas (Lévinas, [1979] 2001: 10), que resulta não do não-saber, mas da inaptidão do conhecimento enquanto tal ao "Infinito do completamente outro". Não-coincidência no desenrolar do tempo dos acontecimentos que chegam ao sujeito: anacronismo, sobrevivência, fantasma do tempo.

O tempo está sempre ligado a um outro da relação e a obra testemunha essa relação, tensão entre si e o outro para-além de si, o outro do tempo sem o qual não há temporalidade psíquica. E esse tempo é marcado pelo enigma da morte, e é de fato esse "mistério", como diz Lévinas, que está no trabalho da obra. Dito de outro modo, o fazer-obra trabalha o tempo da morte, ao menos o tempo do enigma. A obra é o inaudito do tempo, é um monstro de tempo fora do tempo linear, ela é criadora de uma temporalidade própria capaz de levar novamente a linhas psíquicas. Através da obra, a relação com o Outro abre o tempo, na medida em que a obra traz o diferente.

A representação remete sempre ao tempo do ver que nele se deposita (Louis Marin falou de "deposição do tempo na representação pintada"). O espaço visível 
é superfície de traços que testemunham um trabalho temporal ordenado pelo artista, às vezes à sua revelia. $\mathrm{O}$ tempo conserva-se nas camadas superficiais, na espessura invisível da matéria. O retrato constitui a representação que freia o tempo na imagem, enquanto o autorretrato capta o instante da morte. Nesse sentido, o espaço da obra é um espaço de tempo que retém o passado e anuncia o futuro iminente através de figuras imóveis siderantes do fantasma que nos olha. O tempo que opera é estilhaço, irrupção de um real da imagem que revela as rupturas e as fraturas. A ordem do espaço e dos lugares na tela constrói um espaço temporal, o próprio tempo do olhar e da captura pelo olho de uma dimensão espacial. Existe olhar, porque existe um lugar de tempo em que posso depositar meu olhar. Um olhar que pousa é um olhar tomado na história. Sem lugar de tempo, um olhar fica cego e se autodestrói. Esse tempo construído na e pela representação pictural é um tempo configurado segundo as leis do psíquico em que presente, passado e futuro são trabalhados em conjunto com a imagem, de maneira sincrônica: agora é o passado, agora é o presente, agora é o futuro. Uma mesma duração age no tempo de sua realização, a do olhar. Marcas de tempo são dispostas na obra e servem para estabilizar o fluxo temporal: gozo para o olho na contemplação de um tempo estanque, um presente iluminado sob o olhar. Todavia, na imagem pintada, há sempre um ponto de fuga, é o ponto em que nós não estamos na imagem, no tempo da imagem, diríamos.

A pintura dá a ver mostrando um agora, bem como o ato de pintar se fixa na mão que traça ou mancha com linhas e cores. Assim, marcas e imagens compõem um tempo visual de um lugar do faz-de-conta, um no lugar de (o quadro fazendo o efeito do lugar). A pintura retém as traças da mão e as reminiscências da memória visual. Esse dispositivo escópico questiona o reconhecimento daquilo que é pintado, onde se é pintado, quem pinta e quando. O quadro que mostra motivos sobre uma cena fictícia (o no lugar de) organiza um discurso, o que supõe um Outro do discurso. O quadro é transcrição de um tempo que passa em um fora do tempo da crônica. Sua imagem é discrônica, ela é uma imagem alterada pelo tempo que passa e que ela fratura, estilhaça.

O quadro é então uma memória viva desse estilhaço e das imagens que são fraturadas pela dinâmica pulsional da obra. O que é visto é o efeito desse estilhaço, o que (se) passou fica registrado na matéria pictural. A imagem pintada faz-se a testemunha de um acontecimento e se organiza segundo uma sintaxe própria em uma rede de linhas, volumes, cores, formas que farão o engrama, a marca da história até a imagem. Uma cena de história, um mundo de coisas representadas, em referência a um fora que é o real (o referente). O que faz a imagem é o efeito de sentido, a imagem pintada faz sinal para o real (o fora da pintura), ela é uma 
janela que faz fronteira entre dois espaços: o campo do pintor que inclui seu olhar e o campo adiante, para além de seu olhar, espaço da coisa. O olhar é de fato o que quer ver para-além da janela, no espaço da natureza, e devolver então no espaço simbólico, o da pintura, esse impulso a ver.

O espaço pintado torna-se o mostrar e a visada do olhar num posto de fronteira recuado. Entre o querer mostrar e o deixar ver, trava-se o ato de pintar no qual o pintor se enuncia, então, como sujeito. A pintura faz sinal para o real; entre o imemorial e o inesquecível, ela testemunha a falta e o espaço quadro contém essa falta. Dessa falta elaboram-se todos os dispositivos de captação do real que serão dispositivos de tradução. $\mathrm{O}$ devolvido é o resto da visada, entre alusão e ilusão, a fim de que o visto se torne apresentável. O fazer-obra é o testemunho de um tempo visual que se inscreve na matéria. Esse ato é um relatório sobre o que foi visto em um dado tempo e relatado em um lugar que é o próprio espaço pintado. O quadro permite ver a cena visada pelo olhar, é o lugar em que o olhar e o real (a visada) percutam, colidem pela tela estendida, erguida para receber esse acontecimento. O quadro permite, então, aparecer pela reunião das manchas e dos traços, a operação da visibilidade, onde o efeito de sentido e o efeito de pintura se cruzam. Esse encontro é enigmático, revela pouco do impacto do olhar sobre as coisas, mas delas restitui o enigma, a presença da matéria e, como diz Blanchot (1955: 300), "A obra faz aparecer o que desaparece no objeto".

A pintura é, pois, implicação, imagem de um impacto que capta a desaparição, o esvaecimento do instante. Ele é traço da desaparição no tempo, ao reter a visibilidade da desaparição, é eidôlon, um ver puro, uma visão do fenômeno. Essa tomada do sensível na matéria escópica encontra o fantasma que não se esvaece, e o estilhaço próprio desse encontro produz uma fantasmática pictural. A pintura é inscrição ao vivo e em carne do vivente em devir, o incompreensível devir. Essa prática captura o olhar, mas o olhar em seu ponto cego. A pintura não põe à vista, mas capta o olhar em seu ponto que não vê. Ela dá à vista, através de seu ponto cego, o que se ausenta da imagem.

A representação capta o olhar, ela o despe e o desvela, o fascina em seu puro estilhaço. Podemos dizer que o olhar é fascinado, porque é tomado pelo signo da invisibilidade que ele dissimula. De algum modo, se autofascina pelo viés da imagem (imagem-kolossos, isto é, encenação do invisível, do morto, mas em presença, ver supra). No coração da imagem, o tempo escapa então à grandeza matemática, trata-se do tempo do incomensurável, do heterogêneo, que é um tempo de presença, como diria Maldiney. Esse tempo permite o autoengendramento da experiência do ver. A pintura é um sistema de visibilidade, já que opera as condições da visibilidade, preservando a espacialidade originária, ou seja, a distância constitutiva da visão, e se 
inscrevendo desse modo no tempo. Ela dá acesso ao tempo, pois permite o acesso ao visível como tempo do acidente. A condição do visível é a sombra, feixe de luz ocupado pela presença do objeto. É o objeto que faz a sombra, na medida em que a sombra é um momento de história do objeto, um momento no tempo. O olho percebe então essa tensão entre a sombra e a luz, seu turvamento, e é nesse ponto que ele se afeta. Não se pode ver senão turvamento, dizia Goethe, senão afetado, e é, justamente, o que torna a visão acidentada, pouco clara. A pintura é a ocasião de captar esse momento turvo do olhar, pois é nesse lugar que ele desconsiste [déconsiste], que ele faz a experiência da falta da imagem.

Essa falta aparece ou desaparece nas indistinçōes da imagem entre forma e informe, nas dobras e contornos, nos próprios limites do visível. Nesse lugar de turvamento, nesse lugar onde o olho é turvado, enuncia-se a dimensão do tempo. Dimensão do visível, cuja variação consiste na intensidade da persistência ou da fulgurância. O visível é a dialética entre a aparição e a desaparição, aquilo que anda rápido e capta rápido. $\mathrm{O}$ visível é a captação, a tomada ao vivo, o encantamento e logo o desvio através dos sentidos.

\section{O ESPAÇO-PINTURA E O TEMPO DO QUADRO}

O espaço da pintura está ali onde se realizam os modos do aparecer e do desaparecer, da presença e da ausência, em suma, ali onde opera a potência do negativo. Esse espaço do negativo é também um espaço da representação no qual se estende o imaginário. $\mathrm{O}$ espaço se dá à vista através de um dispositivo próprio de orientaçôes (alto, baixo - na frente, atrás - direita, esquerda...). O visível (presente-aparente) irá conduzir para o invisível (ausente-inaparente) através de um sistema de sinais. O olhar permite ver essa dupla camada e, no vai-e-vem entre o presente a ser visto e o ausente a ser entrevisto, fica a tensão, tensão espacial e temporal. O que é percebido é o próprio movimento desse espaço entre o visível e o não-visível, a força do imaginário. O que é captado é a passagem do tempo, o momento em que as coisas se ocultam, escapam ao olhar. $\mathrm{O}$ instante crítico em que o eu se desprende no movimento de um olhar intenso sobre as coisas.

As formas picturais são formas rítmicas, a pintura sendo ritmo do visível. É traça do visível, dos fluxos da visibilidade. A visão do pintor, porém, vê entre os objetos do visível e permite ver aquilo que os separa uns dos outros. De algum modo, ele vê duplo, ao mesmo tempo, os objetos do mundo visível e a parte não visível que os dispóe no ambiente. Uma espécie de visível latente que dá o ritmo e a energia (no sentido da energeia grega) aos objetos. Portanto, ver implica sempre 
em uma vista dupla, de baixo e de cima, é justamente esse cruzamento de vistas o que nos restitui o pintor. $\mathrm{O}$ imaginário é, em pintura, a abertura de um tal espaço, de um tal lugar. Nesse sentido, um quadro constitui sempre um acontecimento (de tempo), pois ele produz abertura e capta um momento de realidade "lido" por um olhar (de história).

O espaço recriado é um espaço de relações, um espaço em que se colocam corpos em tensão, espaço de extensão dos elementos da realidade, dos acidentes visuais. Esse espaço pictural é superfície de deleite, delícia escópica, pois faz estilhaço, pois contém uma potência desejável. Nesse sentido, a pintura é conjugação do estilhaço e do desejável, lugar por excelência do turvo [trouble ${ }^{22}$, lugar em que a visão se turva, como foi dito acima. Turvo para o que é visto aqui sobre essa superfície e para o que é visto fora. Vê-se o que é trazido ao claro, o que é levado ao vivo, à luz, uma questão de motivo, o que faz funcionar o quadro, sua ação de pôr em movimento. O motivo é o visível, o aspecto das coisas, o ritmo do visível. O movimento é temporal, é modulação do tempo. De algum modo, o que está em jogo no coração do quadro é de natureza temporal e visual. A pulsão pictural é implicação de um tempo psíquico, assim como aquilo que é pintado consiste na própria intensidade pulsional, a pulsação psíquica/escópica. A pintura é a operação, a colocação em obra do visível, da aparição, do acontecimento, como diz a pintora Aurélie Nemours. Ela dá conta de um lugar, de um distanciamento ou de um entre-dois, de uma relação entre o dentro e o fora. $\mathrm{O}$ visível invade o campo do olhar, e o trabalho de pintura como o trabalho de imagem é conjugação do tempo e do espaço, do tempo e da memória.

Essa relação entre matéria e cor dá o motivo, interroga o lugar, a mudança de lugar, ou seja, as mudanças de tempo. Todos os gestos do pintor tendem na direção dessa tradução do visível/sensível em imagem criada. Pintar a realidade do ver a partir desse visível, mas privilegiando o entre das coisas. Monet dirá, "O motivo é para mim uma coisa insignificante, o que quero reproduzir é o que existe entre o motivo e eu". O investimento escópico do pintor se situa entre o motivo (da realidade, a paisagem, o retrato...) e o olhar. O desejo do pintor, seu motivo-desejo tende para a operação das condições da visibilidade, de suas próprias variações, o que existe entre as coisas e o olho. As ínfimas partículas do visível/psíquico que se situam nesse espaço de entre-dois vão motivar o gesto de figuração, como se fosse o caso de dar sentido ao não visível, como se fosse o caso de se dar um sentido a partir daquilo que não é visto. "Ce que vise Cézanne, ce qu'il voit, c'est la structure [...], le solide, le durable - la liaison de la variation et de la durée" (Escoubas, 1986: 178) ${ }^{23}$. Donde Cézanne dizer: "Notre art doit donner à la nature le frisson de sa durée avec les éléments, les apparences de tous changements." (Cézanne ci- 
tado por Escoubas, 1986: 178) ${ }^{24}$. O pintor vai desalojar as menores instabilidades para as fixar na matéria. Ele tem o olho nos detalhes e vê claro. Ver assim é ver o tempo, isto é, um tempo que contém todas as instabilidades, todos os paradoxos, todas as coincidências de acontecimentos. Ver entre as coisas é tomar a medida do não-visível, é ver os fantasmas do tempo. $\mathrm{O}$ ato pictural e as operaçóes do olhar de que ele necessita tornam palpáveis as sensaçôes de ar, as sensações de fluência do tempo que passa.

O olhar faz-se olhar-contato e, à medida que o olho toca, ele se aproxima das coisas e as considera. Cézanne fala de realizar suas sensações, as embalar na matéria e restituir as impressões de vista sobre a tela. Em suma, o enigma que envolve a coisa percebida é apresentado, aquilo que emerge do contato entre a percepçãosensação e a visão. Aquilo que a sensação se tornou é também o que se encontra na escrita proustiana, escrita vinda do corpo. Proust "realiza", segundo a palavra de Cézanne, suas sensaçõos na escrita "Comme au moment où je goûtais la madeleine, toute inquiétude sur l'avenir, tout doute intellectuel étaient dissipés. Ceux qui m'assaillaient tout à l'heure au sujet de la réalité de mes dons littéraires et même de la réalité de la littérature se trouvaient levés comme par enchantement" (Proust, 1989: 173) ${ }^{25}$. O encantamento da sensação é o que será devolvido na matéria pictural, literária ou outra : “[...] c'est cette confluence d'intensités omnisensorielles constitutive de la matière même du monde, qui est à peindre" (Escoubas, 1986: $183)^{26}$. É de fato o gesto que carrega consigo todas as sensaçôes e as intensidades do corpo, esses mesmos gestos que farão o quadro.

\section{REFERÊNCIAS}

Blanchot, M. (1955). L'espace littéraire. Paris: Folio/Gallimard.

Blanchot, M. (1959a). Le chant des sirènes. In: Le livre à venir. Paris: Gallimard.

Blanchot, M. (1959b). La question littéraire. In: Le livre à venir. Paris: Gallimard.

Escoubas E. (1986). Imago mundi, topologie de l'art. (Coll. La philosophie en effet). Paris: Galilée.

Fiedler, K. (1887/2003). Sur l'origine de l'activité artistique. Trad. de l'allemand sous la direction de Danièle Cohn. Paris: Éditions Rue d'Ulm/Presses de l'École normale supérieure.

Fiedler, K. (2004). Aphorismes. (Edition établie par Danièle Cohn). Paris: Images Modernes/Danièle Cohn.

Freud, S. (1908/1985). Le créateur littéraire et la fantaisie (Der Dichter und das Phantasieren). In: L'Inquiétante étrangeté et autres essais, N.R.F. (coll. Connaissance de l'inconscient, G.W., VII, 213-233. Trad. Bertrand Féron). Paris: Gallimard. 
Jabès, E. (1984). Le livre des marges. Paris: Fata Morgana.

Lévinas, E. (1979/2001). Le temps et l'autre. Paris: P.U.F., Quadrige, (Fata Morgana) (8 édition).

Masson, C. (2001), L'angoisse et la création - Essai sur la matière, la matière-angoisse et l'enformation. Paris: l'Harmattan, collection dirigée par Alain Brun.

Masson, C. (2010). Temps psychique, temps visuel: essai sur la temporalité psychique considérée du point de vue de l'image. Paris: Les Belles Lettres, collection Encre Marine, La parole en acte.

Nietzsche, F. (1974). Divagations d'un "inactuel”. In: Crepuscule des idoles ou comment philosopher à um coups de marteau (Trad. de Jean-Claude Hémery). Paris: Gallimard, collection Folio/essais.

Nietzsche, F. (1995). La volonté de puissance (Tome I, trad. Geneviève Bianquis). Paris: Gallimard.

Proust, M. (1989). Le temps retourvé - A la recherche du temps perdu VII. Paris: Gallimard.

Van Gogh, V. (1956/1988). Lettres à Théo (coll. L’Imaginaire). Paris: Gallimard.

\section{Notas}

1 N.T.: "Mas uma razão mais grave explicava minha angústia; eu descobria a ação destrutiva do Tempo no momento exato em que eu queria conseguir tornar claras, intelectualizar, em uma obra de arte, realidades extratemporais".

2 N.T.: Trocadilho intraduzível com os homófonos connaît (conhece) e co-naît (conasce).

3 N.T.: “[...] como a feiura do mundo é possível? Utilizei-me da vontade de criar algo belo, da vontade de permanecer nas formas idênticas como de um meio provisório de conservar e de curar. Mas a força de eterna criação, que não é outra senão a obrigação de destruir eternamente, sempre me pareceu fundamentalmente ligada à dor. $\mathrm{O}$ feio é uma maneira de encarar as coisas com a vontade de introduzir um sentido e um sentido novo no que perdeu toda sorte de sentido; é a força acumulada que obriga o criador a sentir que o passado é insustentável, fracassado, digno de ser negado - feio".

4 N.T.: "Nós estamos na vida continuamente entregues a excitaçôes estéticas, transmitidas de modo equitativo por nossos cinco sentidos [...]. Todas as impressōes sensíveis se acompanham de uma sensação estética situada em alguma parte entre as duas extremidades da escala, o prazer e o desprazer".

5 N.T.: "Para conhecermos a colocação em forma de um ser sensível nos diversos aspectos de sua constituição sensível, o melhor é apelar, principalmente, para um desses aspectos: a visibilidade". 
6 N.T.: “[...] o homem só pode desenvolver suas imagens visuais em um grau superior de existência, graças a uma atividade que produz uma configuração visível e verificável enquanto tal, essa atividade não é outra coisa que a atividade artística”.

7 N.T.: "O imenso império do mundo visível se revela inteiramente dependente da matéria mais delicada e, por assim dizer, a mais incorporal, suas formas estão ligadas às formações que o indivíduo cria ao tecer a matéria".

8 N.T.: "O que, em certos movimentos de expressão, permanecem delineados de maneira vaga em todos os seres humanos, alcança no artista um desenvolvimento exclusivo e completamente excepcional; [...] Nós, os outros, somos bloqueados quanto às percepções que nosso olho nos oferece, nosso poder de representação visual encontra rápido seu limite, uma obscuridade impenetrável nos paralisa. $\mathrm{O}$ artista, ao contrário, encontra nele próprio os meios de expressar e captar, com cada vez maior precisão, tais processos vagos e indeterminados, através dos quais nós percebemos globalmente um mundo visível”.

9 N.T.: "como o desenvolvimento de formações determinadas por aquilo que nasce na percepção do olho $[\ldots]$ ".

${ }^{10}$ N.T.: "jogando em sua multidão colorida um jogo de fantasia e de arbitrário".

${ }^{11}$ N.T.: trocadilho intraduzível, já que grande hache sugere "com h maiúscula" e "um grande machado".

${ }^{12}$ N.T.: "O que há, de si, a ser transmitido? - Sem dúvida nada; mas esse Nada é tudo o que possuímos".

${ }^{13}$ N.T.: "Tenho uma lucidez terrível em alguns momentos, nos dias em que a natureza é tão bela e então, não cabendo em mim, o quadro me vem como num sonho".

${ }^{14}$ N.T.: "A relação da fantasia com o tempo é, em geral, muito importante. É possível dizer que uma fantasia flutua de algum modo em três tempos, os três momentos de nossa atividade representativa. O trabalho psíquico se vincula a uma impressão, uma ocasião no presente que esteve em medida de despertar um dos grandes desejos do indivíduo; a partir daí, ele se reporta à lembrança de uma experiência anterior, a maior parte do tempo infantil, no curso da qual esse desejo era realizado; e agora ele cria uma situação que remete ao futuro, que se apresenta como a realização desse desejo, precisamente o sonho diurno ou a fantasia que nele carrega doravante os traços de sua origem, a partir da ocasião e da lembrança. Passado, presente, logo futuro, como se encadeados no cordão do desejo que os atravessa”.

${ }^{15}$ N.T. : "Diante da natureza, é o sentimento do trabalho que me mantém. Mas enfim, é para te dizer que dentro de mim deve ter havido alguma emoção demasiadamente forte que me enfiou nisso e não faço ideia do que pôde ocasioná-la”.

${ }^{16}$ N.T.: "Aprender a sofrer sem se queixar, aprender a considerar a dor sem repugnância, é justamente nisso que se corre o risco da vertigem e, no entanto, seria possível vislumbrar até uma vaga probabilidade de que, no outro lado da vida, perceberemos algumas boas razões 
de ser da dor que, vista daqui, ocupa tanto o horizonte que acaba tomando proporções de um dilúvio desesperador. Sobre isso, sabemos muito pouco, sobre as proporçôes e mais vale olhar um campo de trigo, até mesmo em estado de quadro...”. Grifos da autora.

${ }^{17}$ N.T: "O que pode", pergunta Blanchot, "nos ensinar a obra de arte que possa nos esclarecer sobre as relaçôes humanas em geral?".

${ }^{18}$ N.T.: "esse ponto de ausência, de inanidade, [...] esse rombo, esse intenso e durável vazio... Não pude nem avançar, nem recuar. Estou fixado, alocado sempre em torno de um mesmo ponto, que todos meus livros traduzem".

${ }^{19}$ N.T.: "Parece que um mesmo instinto estético impulsiona o artista a idealizar a natureza e o homem a se vislumbrar, ele e a natureza, em uma forma imagética. Finalmente, foi esse instinto que deve ter causado a construção do olho. O intelecto aparece como a consequência de um aparelho que era estético em sua origem".

${ }^{20}$ N.T.: "O homem que conhece esse estado transfigura as coisas até o ponto em que elas lhe remetem à imagem de sua potência - até o ponto em que elas não são mais do que reflexos de sua perfeição".

${ }^{21}$ N.T.: "A embriaguez apolínea excita principalmente o olho que recebe o poder de visão: o pintor, o escultor, o poeta épico [...]. No estado dionisíaco, ao contrário, é o conjunto da sensibilidade que é excitado e exacerbado a ponto de descarregar de uma vez seus meios de expressão e de intensificar, ao mesmo tempo, seu poder de representação, de imitação, de transfiguração, de metamorfose, todos os modos da arte do mímico e do comediante".

${ }^{22}$ N.T.: O termo trouble também indica distúrbio, desordem.

${ }^{23}$ N.T. : "O que visa Cézanne, o que ele vê, é a estrutura [...] , o sólido, o durável - a ligação da variação e da duração".

${ }^{24}$ N.T.: "Nossa arte deve dar à natureza o frisson de sua duração com os elementos, as aparências de todas as mudanças".

${ }^{25}$ N.T. : "Como no momento em que eu provava a madeleine, toda inquietação com o futuro, toda dúvida intelectual se dissipava. Aqueles que me arremedavam há pouco a respeito da realidade dos meus dons literários e mesmo da realidade da literatura encontravam-se elevados, como que por encantamento".

${ }^{26}$ N.T.: "[...] é essa confluência de intensidades omnisensoriais, constitutiva da própria matéria do mundo, que está por ser pintada”.

Recebido em 10 de agosto de 2009 Aceito para publicação em 25 de maio de 2010 